\title{
PSYCHOSOCIAL SECURITY OF EMPLOYEES IN THE WORK ENVIRONMENT IN THE CONTEXT OF DIVERSITY MANAGEMENT
}

doi: $\quad 10.2478 /$ czoto-2019-0119

Date of submission of the article to the Editor: 05/12/2018

Date of acceptance of the article by the Editor: 18/02/2019

Elżbieta Robak ${ }^{1}$ - orcid id: 0000-0001-8936-4617

Agnieszka Kwiatek ${ }^{1}$ - orcid id: 0000-0003-1252-834X

${ }^{1}$ Czestochowa University of Technology, Poland, elzbieta.robak@wz.pcz.pl;

agnieszka.kwiatek@wz.pcz.pl

\begin{abstract}
Contemporarily, the safety of employees in the work environment is affected by many different factors. Among them, attention should be paid particularly to those that shape the psychosocial safety of employees. The aim of the article is to analyze organizational activities related to diversity management in terms of their impact on psychosocial safety of employees in the work environment. Organizational activities related to diversity management more often appear in enterprises, providing benefits from taking advantage of the various human resources. The effective diversity management is connected with building organizational culture and shaping employee relations in the area of psychosocial safety of employees in the work environment. In the first part of the article, the authors presented the issue of diversity management in relation to the psychosocial safety of employees. The second part shows the results of selected reports and studies related to diversity management in enterprises operating in Poland. Furthermore, the influence of diversity management on the psychosocial safety of employees in the work environment was demonstrated.
\end{abstract}

Keywords: psychosocial security of employees, diversity management, psychosocial risks in the work environment

\section{INTRODUCTION}

The occupational health and safety management system is an important part of the overall business management system because it enables increasing productivity and improving the quality of work and reducing sickness absence. This system includes many different elements, but the human factor plays a key role in it. The issue of this article is included in the broadly understood subject regarding the establishment and implementation of the company's activities in the field of employee safety. Among the different determinants affecting the safety of today's employees play a special role psychosocial risks in the workplace. They pose a risk to their health, both mental and physical, mainly through the indirect action of the mechanism of organizational stress. Risks associated with these psychosocial risk refers to those aspects of the design 
and work management, as well as social and organizational context of work, which can cause injuries to workers psychological or physical. Their negative consequences mean not only a worse functioning of individuals, but in the end they contribute to the less effective operation of the entire company. A number of significant developments towards the management of psychosocial risks have been achieved at the policy level in the European Union (EU) since the introduction of the 1989 European Commission Council Framework Directive 89/391/EEC on Safety and Health of Workers at Work on which a new EU risk prevention culture has since been established, combining legislation, social dialogue, best practices and building partnerships. However, it has been widely acknowledged that initiatives aiming to promote workers' health have not had the impact anticipated both by experts and policy makers and the main reason for this has been the gap that exists between policy and practice (Stavroula and Aditya, 2011).

An interesting way of organizational impact, resulting in increasing the psychosocial safety of employees, is the diversity management strategy. The goal of diversity management is to create and maintain a work environment that is friendly to employees, through respect and sensitivity to their diversity resulting from demographic, social and other characteristics. This means not only creating equal opportunities and observance of the prohibition of discrimination, but above all the way of management that perceives and accepts differences (and similarities) inherent in human resources. The organizational culture open to diversity, leading to shaping the work environment in which every employed person feels respected, appreciated and can fully realize their potential can also significantly affect the psychosocial safety of employees. The aim of the article is to analyze organizational activities related to diversity management in terms of their impact on psychosocial safety of employees in the work environment. Implementation of the assumed goal was subordinated to the arrangement of the issues presented. In the first part, key concepts for the issues discussed were characterized, such as: psychosocial security of employees, psychosocial risks in the work environment and diversity management referring to the subject literature (Crowley, 2018). The second part covers the results of the analysis of research reports containing examples of organizational activities in the field of diversity management affecting the psychosocial safety of employees. In order to fully illustrate the subject matter, interesting practices in this field have been presented in selected enterprises operating in Poland, in the form of a case study. The conclusions summarizes the benefits of diversity management by emphasizing their impact on the psychosocial security of modern employees.

\section{PSYCHOSOCIAL SECURITY OF EMPLOYEES AND DIVERSITY MANAGEMENT - THEORETICAL FOUNDATIONS}

Due to recent EU data showing a high incidence of psychosocial risks to the health of employees and increased problems such as stress, violence, harassment and intimidation at work, a framework was created for the management of psychosocial risks in the workplace (PRIMA-EF). They aim to promote principles and practices at the national and business level. Occupational psychosocial risks relate to aspects of work design and management, its social and organizational contexts that can cause mental or physical damage (Psychosocial Risk Management, 2008; Towards the Development, 2008). 
In the report of the European Agency for Health and Safety at Work, psychosocial hazards are defined as: "any occupational hazard that violates the psychological wellbeing of an employee, including his ability to participate in the work environment among other people [...]; related to the ways of planning, organizing and managing work in its socio-economic context that may cause mental, psychological, physical or illness damage." (European Agency, 2017). Definitions of psychosocial threat emphasize that psychosocial occupational risks are triggered by the occupational stress mechanism, which is often accompanied by workplace violence, contemporary ones are perceived as the most important challenges for occupational health and safety (Stavroula and Aditya, 2011).

Most often, psychosocial risks result from poor planning of work, poor organization of work and poor management of it, as well as from an unfavorable social work environment. They can cause negative psychological, physical and social effects, such as occupational stress, burnout or depression. They carry an increased level of absenteeism, unproductive presence at work (so-called presenteeism - the coming to work of ill employees or unable to function effectively) and increased levels of accidents and injuries. It is estimated that the costs of this situation for enterprises and society amount to billions of euros on a national scale (European Agency for Safety, 2017). Among the disturbances, some are likely to create risks to the enterprises in terms of loss of production, manufacturing capability, human resource, market share and economic losses (Gorzeń-Mitka, 2016). Most often the risk of disturbing psychosocial safety occurs in dysfunctional situations such as, for example, unequal treatment due to a feature or even discrimination. Therefore, attention should be paid to the issue of diversity in the organization.

A organizational culture plays special role in respecting diversity of employees. Building an organizational culture based on the right interpersonal relations contributes to the creation of a positive work atmosphere and trust (Shockley-Zalabak et al., 2010), hence, the psychosocial security of employees in the organization.

Diversity management comes down to seeing differences between people in the organization and conscious development of strategies, policies and programs that create a climate for respecting and using these differences for the benefit of the organization (Gabaldon et al., 2018). Its main goal should be to create a work environment in which every person employed can fully realize their potential and has a sense of psychosocial security. In Polish companies, the above activities are most often undertaken under CSR (Skiba et al., 2017; Zadros, 2016; Starostka-Patyk et al., 2015).

Particularly significant for the specific subject, there are activities in the field of diversity management that shape the culture by:

- taking into account respect for diversity in the values of the company,

- shaping friendly relations,

- supporting employee initiatives related to equality practices in the company,

- openness to employing people who are socially excluded or at risk of marginalization

- monitoring of counteracting discrimination and mobbing

- monitoring of responsibility for managing diversity (Freeman and Cheryl, 2003).

These factors were taken into account by the authors in the following and became distinguishing marks for desk research tests.

Avoiding in the organization undesirable psychosocial phenomena by shaping an appropriate organizational culture allows at the same time to limit the possibility of 
dangerous situations (Zapata-Barrero, 2017). It should be remembered that psychosocial factors, such as discrimination or mobbing, can have an impact on the emergence of situations that disrupt the sense of psychosocial safety.

\section{METHODOLOGY OF RESEARCH}

When analyzing the problem of diversity management in relation to the psychosocial safety of employees, the basic terminological issues concerning the issues discussed in the article are presented on the basis of the literature on the subject. While characterizing the solutions applied by enterprises operating in Poland in the field of diversity management, the desk research method was used. If a study contains more than a single case then a multiple-case study is required. This is often equated with multiple experiments. The simple answer is that the context is different for each of the cases. A multiple or collective case study will allow the researcher to analyze within each setting and across settings. While a holistic case study with embedded units only allows the researchers to understand one unique/extreme/critical case. In a multiple case study, we are examining several cases to understand the similarities and differences between the cases (Baxter and Jack, 2008).

The available studies selected those that allow the answer to the key questions for the undertaken research: What actions in the field of diversity management affect the psychosocial security of employees? To illustrate the subject matter, interesting practices in the field of diversity management implemented in selected enterprises operating in Poland were presented in the form of a case study. The following were used as research methods: literature analysis, desk research and case study.

\section{ORGANIZATIONAL PRACTICES IN THE FIELD OF DIVERSITY MANAGEMENT AND THEIR REFERENCES TO SHAPING THE PSYCHOSOCIAL SAFETY OF EMPLOYEES - RESEARCH RESULTS}

In this study, the authors analyzed the reports from the 1st and 2nd edition of the Diversity Barometer created as part of the Diversity Index project, whose main theme is diversity management. The indicator developed under the Diversity Index is an instrument for analyzing and monitoring diversity management in the workplace, allowing for a real and objective diagnosis of the employer's policy (Cabeza-Garcia and co., 2018). The first edition of the Barometer took place in July-September 2013 (share of 51 entities), in May 2014. in the second (share of 100 entities) (REPORT Responsible Business in Poland 2013; REPORT Responsible Business in Poland, 2014; Womenintheworkplace, 2018).

The following factors / actions were analyzed by companies / institutions within the organizational culture focused on diversity ( $\mathrm{Au}, 2019)$, which were included in the following table (Table 1).:

- focus on the integration of employees (point 1 in the table),

- respect for diversity (on the basis of sex, sexual orientation, disability, origin, ethnicity, age, etc.) (points 2,3,4,5 in the table), (Smith and co., 2018),

- offering flexible forms of work (point 6 in the table),

- information and access to knowledge about diversity (point 7 in the table) (Kompa and Witkowska, 2018).

It can be seen from the above statements that in the analyzed periods the vast majority of companies / institutions undertakes activities aimed at the integration of 
employees (corporate events, integration trips, etc.), (86\% - 2013, $79 \%-2014)$, both large, medium and small.

Table 1

Activities of enterprises in the field of culture regarding diversity management

\begin{tabular}{|c|c|c|c|c|c|c|}
\hline \multirow[t]{2}{*}{$\begin{array}{l}\text { Enterprises and institutions } \\
\text { which: }\end{array}$} & \multicolumn{2}{|c|}{$\begin{array}{ll}\text { Large } & \text { and } \\
\text { medium } & \end{array}$} & \multicolumn{2}{|l|}{ Small } & \multicolumn{2}{|l|}{ Total } \\
\hline & 2013 & 2014 & 2013 & 2014 & 2013 & 2014 \\
\hline $\begin{array}{l}\text { 1. Undertake activities aimed at } \\
\text { the integration of employees } \\
\text { (corporate events, integration } \\
\text { trips, etc.) }\end{array}$ & $91 \%$ & $86 \%$ & $83 \%$ & $78 \%$ & $86 \%$ & $79 \%$ \\
\hline $\begin{array}{l}\text { 2. They directly communicate } \\
\text { that an integration event can be } \\
\text { made with a partner or a partner } \\
\text { from an informal or homosexual } \\
\text { relationship }\end{array}$ & $32 \%$ & $29 \%$ & $31 \%$ & $32 \%$ & $31 \%$ & $31 \%$ \\
\hline $\begin{array}{l}\text { 3.They pay the contribution to } \\
\text { PFRON, because they have less } \\
\text { than } 6 \% \text { of people with disabilities } \\
\text { among employees }\end{array}$ & $77 \%$ & $71 \%$ & $7 \%$ & $26 \%$ & $37 \%$ & $37 \%$ \\
\hline $\begin{array}{l}\text { 4. They have jobs adapted to the } \\
\text { needs of people with disabilities }\end{array}$ & $73 \%$ & $71 \%$ & $10 \%$ & $56 \%$ & $37 \%$ & $59 \%$ \\
\hline $\begin{array}{l}\text { 5. They ensure that the days and } \\
\text { hours of work take into account } \\
\text { the religious and religious needs } \\
\text { of employees }\end{array}$ & $45 \%$ & $62 \%$ & $66 \%$ & $63 \%$ & $57 \%$ & $62 \%$ \\
\hline $\begin{array}{l}\text { 6. They offer flexible forms of } \\
\text { employment }\end{array}$ & $77 \%$ & $43 \%$ & $79 \%$ & $40 \%$ & $78 \%$ & $41 \%$ \\
\hline $\begin{array}{l}\text { 7. In the internal document they } \\
\text { have written the rules of using } \\
\text { flexible forms of employment }\end{array}$ & $55 \%$ & $86 \%$ & $34 \%$ & $78 \%$ & $43 \%$ & $79 \%$ \\
\hline
\end{tabular}

Source: (REPORT Responsible Business in Poland 2013; REPORT Responsible Business in

Poland, 2014)

However, only a little more than $1 / 3$ of companies / institutions undertake initiatives to respect diversity. There has been a significant drop in job opportunities in flexible forms of employment $(78 \%-2013,41 \%-2014)$, which is inversely proportional to declarations and provisions of the use of flexible forms of employment in an internal document $(43 \%-2013,79 \%-2014)$. This may indicate that the declarativeness of the companies / institutions surveyed does not always translate into specific diversity activities. However, many of them are introducing diversity management into their standards.

\section{EXAMPLES OF GOOD PRACTICES IN THE FIELD OF DIVERSITY MANAGEMENT APPLIED IN ENTERPRISES OPERATING IN POLAND - A CASE STUDY}

The other form of depicting the analyzed problem are examples of good practices in the field of diversity management applied in enterprises operating in Poland. It was presented on the basis of four organizations, their approach to the issue of diversity and initiatives undertaken in this area (Łączy nas różnorodność, 2016) 
BPH is part of the international GE corporation that operates in over 100 countries and employs nearly 300,000 employees. The diversity of human resources possessed has meant that the bank has been conducting activities for diversity for many years covering four areas: development programs, good practices, internal communication and PR. Examples of development programs are programs for gifted women, such as the Future Leaders Program and Executive Coaching, as well as many years of activity of the GE Women's Network, focused on promoting women's development, improving their managerial skills and career path planning, and enabling them to establish cooperation with other women, also from outside the enterprise. Thanks to another myConnections initiative, i.e. regular meetings in small groups, members can share knowledge, gain contacts and broaden their horizons. As part of good practices, a policy of counteracting violence in the workplace was introduced, as well as the Babymagination program, responding to the needs of employees who have just become parents. Among the diversity management initiatives at the bank, the diversity management training for managers and the mentoring program are also worth emphasizing.

British American Tobacco Polska is part of the British American Tobacco Group an international tobacco company that sells its products on over 200 markets around the world. The company, appreciating the diversity of employees, informs employees about their rights and conducts educational activities. One of the typical activities that support diversity in the workplace is the improvement of qualifications and professional skills regardless of the position and grade occupied. The company has an open training system in which employees at all levels can participate. The principles of equal treatment are also observed in the recruitment process. For this purpose, a special communication channel was established - the White Line, which allows all employees to report irregularities in the conduct of other employees, bypassing the official route.

KPMG is an international network of auditing and advisory companies, also operating in Poland since 1990. In its several locations in Poland, employment is in total over 1,800 people. Among key company values, which are a reference point for all employees and are a determinant of KPMG's organizational culture in Poland, respect for individuality of employees plays a significant role. In practice, this means counteracting all forms of discrimination in all areas of the company's activity (training, work, employee benefits, development and promotion). Employees of the company are different generations, mainly $\mathrm{X}$ and $\mathrm{Y}$, who work together, and exchange experiences while learning from each other. Recruitment to the company ensures equal treatment of candidates with regard to age, health, gender, sexual orientation, family status and place of origin. In addition, regulations have been introduced to enable employees to report behaviors and attitudes that violate ethical standards (including the policy of equal treatment), as well as to consult difficult situations in this area. Other KPMG initiatives relevant to diversity management include: the Young Mama program, employee exchange as part of the Global Opportunity and Tax Trek program, including employee partners in employee benefit programs, including spouses.

The presented examples of enterprises undertaking diversity management initiatives emphasize the principles of equal treatment of employed persons and counteracting all forms of discrimination in all areas, including: recruitment, development, promotion, training, etc. Confirmation of the involvement of companies are such examples of 
activities as: support programs professional development and managerial skills of women, programs supporting the balance between work and personal life of employees, including mainly addressed to parents. It is also worth emphasizing initiatives in the field of informing and educating employees about their rights as well as diversity management training for managers.

With regard to the psychosocial safety of employees, special visibility requires: an adopted policy of counteracting violence in the workplace, monitoring of mobbing and discriminatory activities, regulations enabling employees to report behaviors and attitudes violating ethical standards (including the policy of equal treatment). It is also worth noting the activities in the field of creating special communication channels that allow all employees to report irregularities, eg. mobbing. Very important are also the initiatives of the described companies in the area of surveying the opinions and needs of employees and the organizational climate.

\section{CONCLUSION}

As is clear from reports and research papers more and more companies recognizes that the diversity of the human resources is their strength, and provides opportunities to compete effectively in today's dynamic market. Diversity management means, generally speaking, a skillful use of differences inherent in people. This allows you to create a work environment in which every employee will feel valuable, the talents of all people will be fully appreciated and the organization's goals will be achieved. It is not easy to treat diversity not as a burden but as an asset, but research shows that it is beneficial. In the context of the issues to be addressed, it should be emphasized that a well-developed strategy of activities related to diversity management, having its roots in the adopted system of values, can significantly affect the psychosocial safety of employees. However, the sense of safety of the workplace will not be ensured only by the procedures and programs in force in the enterprise - if they are not supported by the organizational culture open to diversity. Organizational culture based on respect for diversity combined with appropriate changes in management as well as clear rules and developed procedures can significantly affect the psychosocial safety of employees in the work environment. Only complete understanding and acceptance as well as treating diversity in terms of values can be the basis for increasing the sense of psychosocial security of employees in organizations.

\section{Reference}

Au, A., 2019. Thinking about Cross-Cultural Differences in Qualitative Interviewing: Practices for More Responsive and Trusting Encounters. The Qualitative Report, 24(1), 58-77. Retrieved from https://nsuworks.nova.edu/tqr/vol24/iss1/5.

Baxter, P., Jack S., 2008. Qualitative case study methodology: Study design and implementation for novice researchers. The Qualitative Report, 13(4), 544-559. Retrieved from http://www.nova.edu/ssss/QR/QR13-4/baxter.pdf.

Cabeza-Garcia, L., Fernandez-Gago, R., Nieto, M., 2018. Do Board Gender Diversity and Director Typology Impact CSR Reporting? European Management Review, 15(4), 559-575, DOI: 10.1111/emre.12143.

Crowley, N. ,2018. European network of legal experts in gender equality and nondiscrimination, Equality bodies making a difference. European Commission, Brussels., equality_bodies_making_a_difference.pdf. 
European Agency for Safety and Health at Work Annual Activity Report, 2017. https://osha.europa.eu/pl/tools-and-publications/publications/annual-activity-report2017-0.

Freeman, Cheryl. 2003. Recruiting for diversity. Women in Management Review 18(1/2), 68-76.

Gabaldon, P., Kanadli, S.B., Bankewitz, M., 2018. How does job-related diversity affect boards' strategic participation? An information-processing approach. Long Range Planning, 51(6), 937-952, DOI: 10.1016/j.Irp.2018.02.005

Gorzeń-Mitka, I.,2016. Leading Risk Management Determinants of Small and Medium-Sized Enterprises (SMEs): An Exploratory Study in Poland, Entrepreneurship. Business and Economics. 1, (ed.) BILGIN M. H., DANIS H., Cham, 289-298, DOI:10.1007/978-3-319-27570-3_23.

Kompa, K., Witkowska, D., 2018. Gender Diversity in the Boardrooms of Public Companies in Poland: Changes and Implications. Montenegrin Journal Of Economics, 14(1), 79-92, DOI: 10.14254/1800-5845/2018.14-1.6.

Łączy nas różnorodność, 2016. Przewodnik po Karcie Różnorodności. Forum Odpowiedzialnego Biznesu, http://odpowiedzialnybiznes.pl/karta-roznorodnosci.

Psychosocial Risk Management - European Framework: Enterprise Level, 2008. Prima-ef Consortium, www.prima-ef.org.

REPORT Responsible Business in Poland 2014, www.responsibilitybussines.pdf.

Shockley-Zalabak, P.S., Morreale, S., Hackman, M., 2010. Building the High-Trust Organization: Strategies for Supporting Five Key Dimensions of Trust. JosseyBass, San Francisco.

Skiba, Ł., Albrychiewicz-Słocińska, A., Paven, I. Poor, J., Czarnecka A., 2017. "Humanity" as Part of the CSR Strategy, Managerial Trends in the Development of Enterprises in Globalization Era. ed. Kosiciarova, I., Kadekova, Z., 7th International Conference on Management „Managerial Trends in the Development of Enterprises in Globalization Era" (ICoM 2017), Nitra, Slovak, 669-677.

Smith, J. and co., 2018, Added Benefits: How Supporting Women Faculty in STEM Improves Everyone's Job Satisfaction, Journal Of Diversity In Higher Education, 11(4), 502-517, Washington, DOI: 10.1037/dhe0000066.

Starostka-Patyk, M., Tomski, P., Zawada, M., 2015. Diversity Management as a Part of Corporate Social Responsibility Policy. Procedia Computer Science, 1038-1045, DOI:10.1016/j.procs.2015.09.055

Stavroula, L., Aditya, J., 2011. The role of policy for the management of psychosocial risks at the workplace in the European Union. Safety Science, 49(4), 558-564, https://doi.org/10.1016/j.ssci.2010.02.002.

Towards the Development of the European Framework for Psychosocial Risk Management at the Workplace, 2008. Institute of Work, Health \& Organisation, ed. Stavroula, L. , SALTSA, http://www.prima-ef.org/preliminary-report.html

Women in the workplace, Women_in_the_Workplace_2018.pdf

Zadros, K., 2016. Can CSR be the Duty of the Company?, Trends of Management in the Contemporary Society, ed. Formankova, S., Mendelova, 6th International Conference on Management. Trends of Management in the Contemporary Society (ICoM), Brno, Czech Republic, 348-351.

Zapata-Barrero, R., 2017, Methodological interculturalism: breaking down epistemological barriers around diversity management, ETHNIC AND RACIAL STUDIES. 42(3), 346-356, Oxon, DOI: 10.1080/014 19870.2019.1538527. 